\title{
Trombosis de la arteria renal
}

\author{
Renal artery thrombosis \\ Carolina Andrea Pérez Cruz, ${ }^{*}$ Asael Guadalupe Flores Mata, ${ }^{*}$ \\ Carolina González Vergara, ${ }^{*}$ Lizbett Hidalgo Pérez ${ }^{\ddagger}$
}

Citar como: Pérez CCA, Flores MAG, González VC, Hidalgo PL. Trombosis de la arteria renal. Acta Med GA. 2022; 20 (1): 108-110. https://dx.doi.org/10.35366/103571

La trombosis de la arteria renal se presenta con una incidencia menor de $2 \%$ de todas las trombosis abdominales. ${ }^{1}$ Se debe incluir en los diagnósticos diferenciales de un síndrome doloroso abdominal.

Se presenta el caso de una mujer de 68 años hipertensa, fumadora (índice tabáquico de 24), que presenta dolor súbito tipo cólico en hipogastrio, intensidad 10/10, irradiado hacia región lumbar derecha. En exploración física presenta diaforesis, dolor a la palpación en fosa iliaca derecha. Creatinina $1.14 \mathrm{mg} / \mathrm{dL}$, lactato deshidrogenasa (DHL) $189 \mathrm{U} / \mathrm{L}$.

En fase arterial, la angiotomografía evidencia amputación de arteria renal derecha desde su origen con la consecuente ausencia de fase nefrográfica (Figuras 1 y 2).
Se realiza nefrectomía derecha, con reporte por anatomía patológica de necrosis cortical y hemorragia reciente de $95 \%$ asociadas a trombosis arterial.

A nivel del hilio se encontraron cuatro arterias renales, resultado de la bifurcación de una arteria renal principal como variante anatómica (Figura 3).

Se debe sospechar trombosis de la arteria renal con dolor abdominal súbito, elevación sérica de DHL y/o hematuria y riesgo de evento trombótico (fibrilación auricular, tabaquismo, dislipidemia y ateroesclerosis). ${ }^{2,3}$

La angiografía es el estudio de elección y es positiva en $100 \%$ de los casos, seguida de la angiotomografía, la cual es actualmente el estudio de elección por la mayor
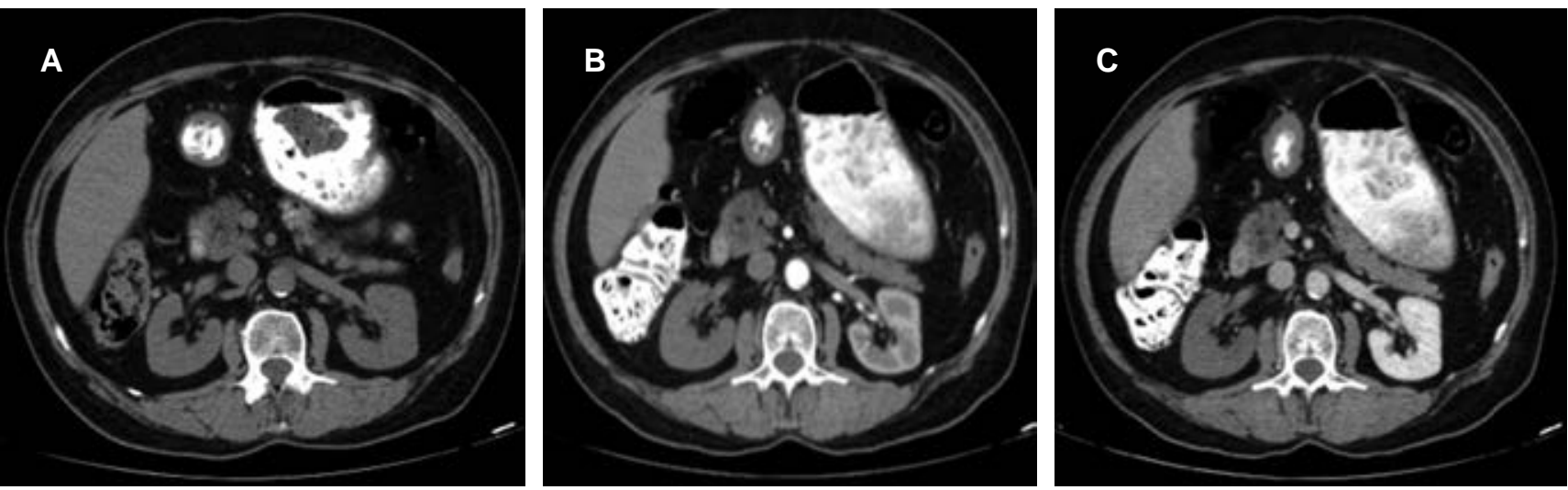

Figura 1: Estudio angiotomográfico. A) Corte axial en fase simple sin evidencia de alteraciones. B) Corte axial en fase corticomedular que evidencia amputación de arteria renal derecha desde su origen y sin realce de la corteza tras la administración de contraste intravenoso. C) Corte axial en fase nefrográfica que visualiza persistencia de la amputación de arteria renal derecha, sin realce del parénquima renal.

* Departamento de Radiología e Imagen.
* Departamento de Anatomía Patológica.

Hospital Angeles Mocel. México.

Aceptado: 07-09-2020
Correspondencia:

Carolina Andrea Pérez Cruz

Correo electrónico: caroolina_0793@hotmail.com

www.medigraphic.com/actamedica






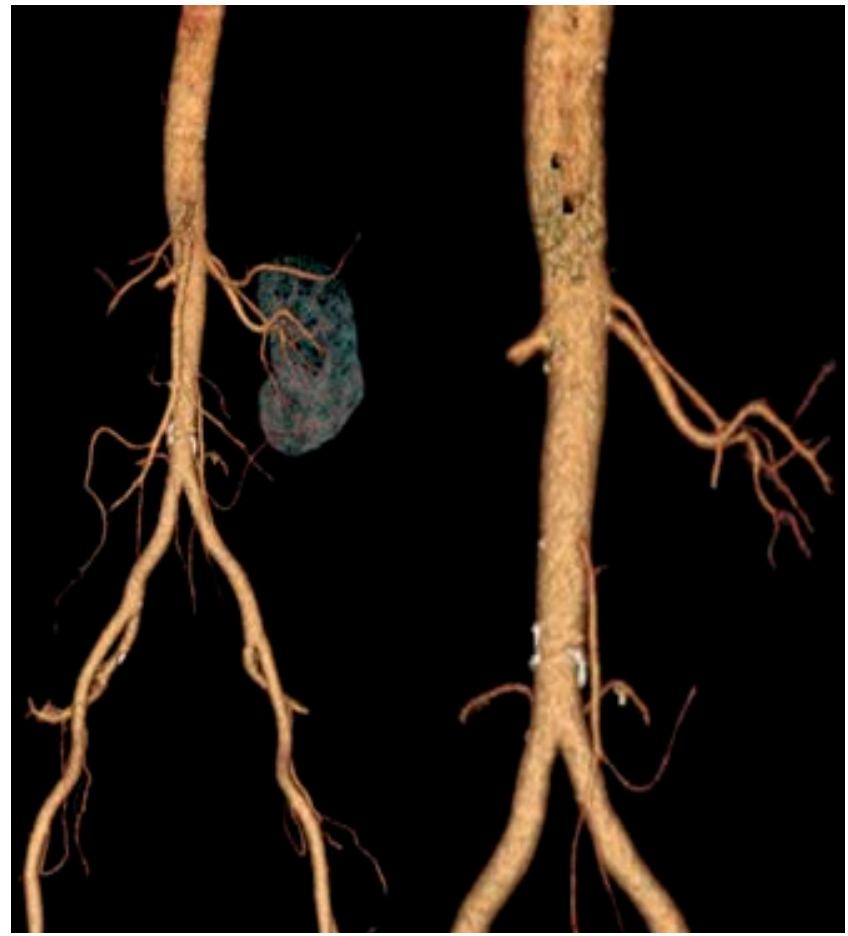

Figura 2: Reconstrucción 3D del estudio angiotomográfico que evidencia amputación de arteria renal derecha y ausencia de opacificación del riñón derecho.

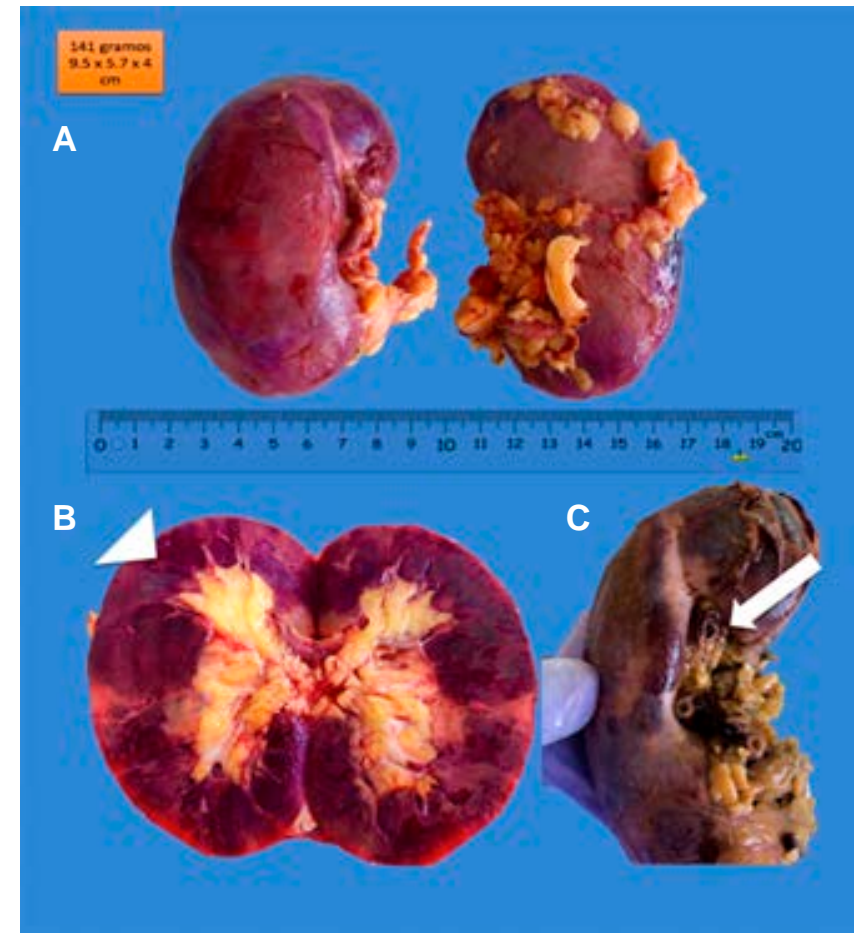

Figura 3: A) Pieza de nefrectomía derecha en vista anterior y posterior de $9.7 \times 5.7 \times 4 \mathrm{~cm}$. B) Corte coronal que demuestra necrosis cortical difusa (punta de flecha). C) Hilio renal con evidencia de cuatro arterias con trombo organizado y hemorragia (flecha).
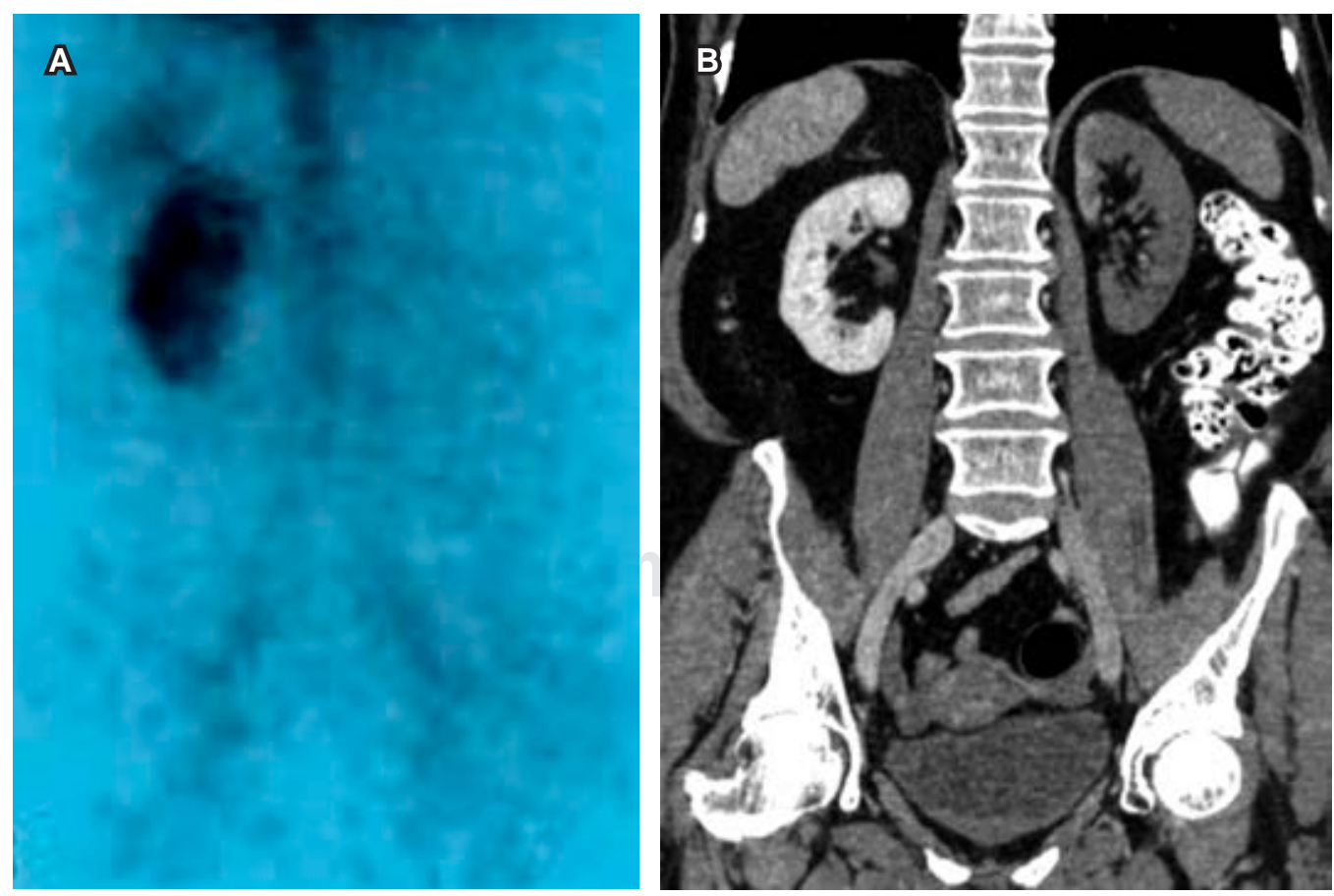

Figura 4:

A) Gammagrama renal en posición posteroanterior realizado con mercaptoacetiltriglicina (MAG3), que corrobora la hipoperfusión renal total derecha. B) Reconstrucción coronal "invertida" comparativa al gammagrama con hipoperfusión del riñón derecho. 
disponibilidad y por ser menos invasiva para el paciente. Los datos tomográficos de diagnóstico son: riñón hipodenso en fase arterial consistente con dato de hipoperfusión renal, aspecto de masa y ausencia de realce en forma de cuña. ${ }^{1,4}$ La morfología cuneiforme puede traducir isquemia parcial. La correlación con la cínica y laboratorios permite realizar el diagnóstico diferencial con pielonefritis. De manera oportuna permitirá la intervención temprana y adecuada para preservar la viabilidad renal y deberá considerarse en pacientes con factores de riesgo aun con cuadro clínico inespecífico, ya que el estudio tomográfico simple es inservible en este padecimiento.

En caso de que el estudio angiotomográfico sea negativo y presente una alta sospecha de trombosis renal, el estudio alternativo será un gammagrama renal específico realizado con $\mathrm{Tc}^{99} \mathrm{~m} / \mathrm{DTPA}$ o con MAG3 (Figura 4). ${ }^{4}$

\section{REFERENCIAS}

1. Sosa-Barrios $\mathrm{H}$, Jiménez-Álvaro $\mathrm{S}$, Gomis-Couto A, Rivera-Gorrin M, Blázquez J, Burguera-Vion $\mathrm{V}$ et al. Oclusión de arteria renal y fibrinolisis local intravascular. NefroPlus. 2014; 6 (1): 57-60. doi: 10.3265/NefroPlus.pre2013.Jul.12068.

2. Al-Katib S, Shetty M, Jafri SM, Jafri SZ. Radiologic assessment of native renal vasculature: a multimodality review. RadioGraphics. 2017; 37 (1): 136-156. doi: 10.1148/rg.2017160060.

3. Nandwani A, Pathania D, Jha PK, Kher V. Renal artery thrombosis with renal infarction: a rare cause of acute abdomen. Indian J Nephrol. 2017; 27 (4): 313-315. doi: 10.4103/0971-4065.183581.

4. Lopez VM, Glauser J. A case of renal artery thrombosis with renal infarction. J Emerg Trauma Shock. 2010; 3 (3): 302. 